\title{
A future for marine fisheries in Europe (Manifesto of the Association Française d'Halieumétrie)
}

\author{
D. Gascuel ${ }^{a, b,{ }^{\star}}$, N. Bez ${ }^{a, c}$, A. Forest ${ }^{a, d}$, P. Guillotreau ${ }^{a, e}$, F. Laloë ${ }^{a, c}$, J. Lobry ${ }^{a, f}$, S. Mahévas ${ }^{a, d}$, B. \\ Mesnil $^{a, d}$, E. Rivot ${ }^{a, b}$, S. Rochette ${ }^{a, b}$ and V. Trenkel ${ }^{a, d}$
}

\author{
${ }^{a}$ Association Française d'Halieumétrie, France \\ ${ }^{b}$ Pôle halieutique Agrocampus Ouest, France \\ ${ }^{\mathrm{c}}$ IRD, France \\ ${ }^{d}$ Ifremer, France

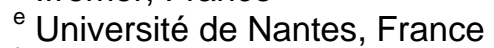 \\ ${ }^{\dagger}$ Cemagref, France
}

*Corresponding author : D. Gascuel, email address: Didier.Gascuel@agrocampus-ouest.fr

\begin{abstract}
:
We, members of the Association Française d'Halieumétrie, share the conviction that European fisheries have a future. It is time to get off the wrong track. Radical change is required to embark on the path of sustainable development and truly implement the ecosystem approach to fisheries. Today, high fishing pressure is deployed to catch a rare resource, which in return is responsible for the rarity. We must reverse the situation: an abundant resource that affords high catches applying moderate fishing pressure. All management tools and especially all actors must be mobilized. The transition is not simple, and European solidarity must accompany the changes. It is well worth the effort. By reducing fishing pressure, it will be possible in the medium term to restore fish stocks, to make ecosystems return to good ecological status, to stabilize and even increase catches and to considerably improve economic efficiency. This is obviously in the interest of fishers but it is also in the interest of future generations and all users of this common heritage that is the sea.
\end{abstract}

\section{Research highlights}

To ensure the sustainable development of European Fisheries, radical changes are required. We define what truly implementing the ecosystem approach to fisheries means. Reaching MSY is a first (difficult) step to drastically decrease the fishing pressure. Overcapacity is not everything, access right must be regulated. Strengths and weaknesses of major management tools (ITQ, MPA, LTMP...) are highlighted.

Keywords: Access regulation; Ecosystem approach to fisheries; European Common Fishery Policy; ITQ; MPA; MSY; Management plan; Overcapacity; Subsidies 


\section{Introduction}

European marine fisheries are in crisis, confronted with the triple challenge of dwindling natural resources, a global market that is pushing prices down and increasing energy costs. Year upon year, production stagnates, the number of fishers decreases and ships age or are sent to the scrap yard. Thus the sector's long-term prospects points towards a slow death. Many signs seem to indicate that marine fisheries are inevitably condemned to decline in Europe, and our future supply of sea products might mainly depend on aquaculture or developing countries. But at the same time, some forces are already in move to change fisheries management, providing potential tracks towards a future for fish and fishermen.

We scientists, members of the Association Française d'Halieumétrie $(A F H)^{1}$, refute the perspective of decline. We believe, on the contrary, that marine fisheries have a future in Europe. That it is possible for the sector to embark on a path of sustainable development, combining ecological sustainability, economic viability and social fairness. But we believe that this requires far reaching changes that cannot occur without the participation of all stakeholders.

A "window of opportunity" is currently opening to change the situation. In France, a debate took place on the occasion of the "Grenelle de la Mer" (April-July 2009) and the "Assises de la pêche" (October-November 2009) organized by the French ministry for the environment. In Europe, profound changes are announced in the context of reforming the Common Fishery Policy and the implementation of the Marine Strategy Framework Directive. We believe that it is the responsibility of 
researchers to share their findings with the rest of society. Thus we wish to contribute to the debate and try to shed light on the issues at stake.

This paper is a synthesis of our contribution to the consultation carried out by the European Commission regarding the Common Fisheries Policy green paper (EC, 2009). It stems from discussions among scientists from various research bodies representing diverse disciplines. As common in the scientific community we do not all necessarily endorse the same approaches (e.g. Pauly, 2009; Hilborn, 2010). However, we have in common our involvement in fisheries science and our desire to contribute to the search for sustainable solutions, so that marine fisheries can have a future in Europe.

\section{The sea is sick, suffering from human attacks}

Our and other scientists research has clearly shown, and the general public is well aware of it, that the sea is suffering from multiple attacks: marine pollution, coastal habitat destruction, biological invasions, etc (e.g. Lorance et al., 2009, Halpern et al., 2008; Rochette et al., 2010; OSPAR, 2010), but also - and especially - overfishing. Results are unambiguous: the abundance of most commercial fish stocks is at its lowest level ever, the functioning of the ecosystems is disturbed, biodiversity is threatened, and the loss of jobs related to the depletion of resources has steadily continued over the last 20 years (MEA, 2005; Pauly et al., 2005; FAO, 2009).

In European Union waters, decreasing fishing pressure has been the purpose of fisheries management for decades. As a result the decline of several target stocks has been halted, but the situation continues to deteriorate for others (ICES, 2009; Sparholt et al., 2007, Villasante 2010). And abundance levels remain low overall: $80 \%$ of EU stocks assessed by the International Council for the Exploration of the Sea (ICES) are at abundance levels below those corresponding to maximum sustainable yield (ICES, 2009; EC, 2009 and 2010). This is the case, in particular, for demersal fish species whose stocks sizes have generally been divided by 5 , or even by 10 or more, by overfishing (Froese et al., 2008; Froese and Proelss, 2010; Worm et al., 2009). In other words, where there used to be 10 tons of fish on the bottom, today there are less than 1 or 2 tons.

The decrease in abundance of target species is accompanied by truncation of their demographic structure leading to greater resource instability with a knock on effect on their preys, predators and competitors, and the whole ecosystem (Pauly et al., 1998; Jackson et al., 2001). At the same time, certain fishing gears have strong impacts on habitats (Turner et al., 1999). These ecosystem effects remain difficult to quantify but are no less significant. Species composition is modified in numerous ecosystems, with the increase of species with short life cycles to the detriment of longer lived demersal species (some of which like cod or hake are emblematic of European fisheries). Significant changes in the functioning of trophic networks, changes that convey a diminution of the functional biodiversity of the ecosystems, have also been observed (Heath, 2005; Pauly and Watson, 2005; Worm et al., 2006).

In European waters, the decline often dates back many years and low abundances have lasted for several decades (Hutchings et al., 2010, Serchuk et al., 1996; Worm et al., 2009). This has two consequences. On one hand, entire generations of fishers and managers have only known this degraded state and therefore tend to consider it the "normal" system state. The occurrence of a single good recruitment is then interpreted as a return to good stock conditions, while most often it is unfortunately only a temporary event (Rice, 2006); thus there is a push for immediate increase of TACs and the recruits might be fished out before they could contribute to rebuilding the stock. On the other hand, scientists often lack observations from earlier periods, which makes it difficult to establish reference points. In both cases, we are somewhat used to "managing shortages."

Let's be clear: Humans are part of ecosystems and it is therefore inevitable that they would have an impact on the resources they are using. What creates the problem is not the fact that fishing reduces the abundance of target resources or modifies ecosystem functioning, but rather the fact that this impact reaches levels such that it compromises the fishing activity itself. Fishing leading to diminished total catches is both economically absurd and ethically questionable. 


\section{Fishers are themselves victims of overfishing}

Fishers are the first victims of the global and common overfishing problem. French statistics show that the number of sailors and fishing vessels has been halved over the past 20 to 25 years and the production of demersal fish over the last 40 years (from FAO and Ifremer websites); similar decreases have occurred in other European countries (Villasante, 2010). As a result, the entire sector is affected, with the disappearance of suppliers and processors, the closing of fish auctions and the breakdown of the economic and social lives in some coastal zones (World Bank and FAO 2009). The capacity of the fishing sector to contribute to national planning goals is called into question (Cléach, 2009).

Today, low abundances translate into low yields and elevated fishing costs. They are a strong structural element of the fishing crisis, and explain, at least in part, the weak economic returns of some fleets. Overfishing creates variability in catches, strong dependence on recruitment and therefore on environmental variations. This variability makes fisheries management difficult and does not allow the industry to act cost efficiently.

Other factors aggravate the economic situation such as the increase of oil prices and low fish prices caused by strong internationalization of sea products (Sumaila et al., 2008; Anderson, 2003; Abernethy et al., 2010). However, let's not make a mistake: these factors play an evident role, but the crisis is in reality even deeper. It fundamentally stems from the depletion of ecological capital (Jansson et al., 1994).

Many players in the fishing sector are used to low catches and unpredictable economic returns and tend to believe that the sector can only survive economically with massive public aid (Mesnil 2008). Numerous economic analyses show, however, that this situation is not inevitable. Far from opposing each other, the goals of ecological conservation and sustainable development are inextricably connected. There is no sustainable future for the fishing sector in France or Europe without restoring ecosystems to a healthy state. And without doubt, there is no possible conservation of biodiversity without the involvement of fishers. But this involves a rather radical change in management methods.

\section{The Ecosystem Approach to Fisheries (EAF) is a necessity}

In the medium-term, we must move resolutely towards an EAF. "The purpose of an EAF is to plan, develop and manage fisheries in a manner that addresses the multiplicity of societal needs and desires, without jeopardizing the options for future generations to benefit from a full range of goods and services provided by marine ecosystems" (FA0, 2003; Garcia et al., 2003). This definition includes the notion of future generations. The ecosystem approach to fisheries is therefore an application of the sustainable development principle.

The EAF requires three things:

1. The impacts of fishing need to be taken into account, not only on target species, but more globally on all ecosystem components and functioning. Evaluations, diagnostics and regulatory measures at the stock level remain necessary. But they should be completed by more integrated approaches, better able to evaluate the ecosystem health and the economic viability of fisheries, by integrating multi-species and multi-fleet dimensions.

2. The effects of other anthropogenic impacts should also be evaluated, in particular pollution, habitat destruction, and biological invasions. This general approach is defined by the European Marine Strategy Framework Directive (EC, 2008).

3. The Millenium ecosystem assessment carried out under the auspices of the U.N. contributed to raising awareness of the various services that marine ecosystems provide to mankind (MEA, 2005). Beyond producing food, they also produce energy, purify water, regulate biogeochemical cycles and the climate, preserve species or genetic biodiversity, and support cultural and tourist activities. Fishing interacts with them and cannot be managed in isolation. 
The EAF calls for new scientific questions and an unprecedented research effort. New multidisciplinary approaches, new indicators and new models are being developed to analyze complex systems while recognizing their variability. Considerable efforts are still required, on one hand to build (costly) observation systems on marine ecosystems, and on the other hand to integrate social sciences to better understand economic dynamics and fisher behavior. All this research should be conducted on the long term, aiming for scientific excellence and international collaboration.

At the same time, means must be granted to develop and maintain scientific expertise and training. Interfaces have developed since the last reform of the European Common Fishery Policy in 2002, especially with the creation of the Regional Advisatory Councils (RACs). But there is still a lack of appropriate structures to develop and get recognition for applied research and expertise, at the interface between science, management and policy.

While the long-term approach is still under construction, we feel that the EAF can and must have operational implications for fisheries management in the short to medium-term. We identify four implications:

1. The principle of "minimizing" the ecological impact of human activities, established in various official documents from the European Community (e.g. EC, 2002), deserves to be applied in a more resolute way. Naturally, this principle is not understood in the absolute, but in reference to a given exploitation situation. It completes economic viability criteria and should lead to consider questions such as: is it possible to continue fishing as much, and possibly even more, while diminishing the impact of the fishing on the ecosystem? Shifting from the current approach, usually based on an estimate of the maximum acceptable ecological impact, to such a principle of minimization, would have huge consequences, for instance regarding targets used in fisheries policy.

2. The current stock-based approach of European fisheries management is insufficient and the métier based approach deserves to be developed. In particular for establishing economic and social balance sheets. Bioeconomic modeling and, more generally, the contribution of the social sciences are strongly required.

3. The definition of relevant spatial ecosystem management units and adequate scientific advice on ecosystems health require developments. Achieving the Marine Strategy Directive Framework goal of a good environmental status for marine ecosystems in 2020, implies an in depth revision of the Common Fishery Policy, and some huge changes in the organization of the scientific advice system.

4. The multiple services rendered by marine ecosystems concern multiple users. For this, a more collective governance must be developed (especially within Regional Advisory Councils), including sharing rights and responsibilities towards marine resources.

\section{Reaching MSY requires considerable changes}

In Europe, reaching the maximum sustainable yield (MSY) for target species is the first step towards an EAF, undoubtedly insufficient but absolutely necessary to minimize the ecological impact of fishing activities. It is furthermore a binding obligation defined in international fishery agreements (UNCLOS, 1982; UNFSA, 1995), and a commitment to which many States, notably the EU, subscribed at the Johannesburg summit in 2002.

Honoring this commitment requires engaging considerable changes now. Assessment conducted under the auspice of ICES show that it is necessary to divide fishing pressure by 2 or 3 , or even more for the majority of the large demersal European stocks (Sparholt et al., 2007). At the same time, the abundance of these stocks is expected to be often multiplied by 3 or 4 (Froese et al., 2008; from ICES, 2009). Therefore, it is not a question of marginal adjustments, but of drastic changes. Today, to catch a rare resource, a high fishing pressure is necessary, which in return is responsible for the rarity. We must reverse the situation: an abundant resource that affords high catches applying moderate fishing pressure. 
Reaching MSY by a decrease of fishing pressure will likely have limited effects on total catches (available yield per recruit estimates from ICES working groups indicate a gain of 5 to $30 \%$ for the main European stocks). If in addition size selectivity is changed, an even higher increase in potential catches is expected (Froese and Proelß, 2010; Froese et al., 2010). The economic and ecological benefits would be considerable:

- $\quad$ Reduced fishing costs. For the same number of fishers (supposing each decreases effort), the economic return from fishing will increase considerably. Additionally, stock rebuilding will lead to exploiting a greater number of year-classes, resulting in greater year-to-year stability of catches, and therefore a decrease in economic risk (Mardle et al., 2008).

- Reduced impacts on ecosystem functioning. The current state of scientific knowledge does not allow us to predict all implications of such a change. Will it be sufficient to return ecosystems to "good health"? This is currently difficult to say. However, it is certain that reducing the impact can only be beneficial and a step towards the precautionary approach at the ecosystem scale.

The return to higher abundances will also have the beneficial consequence of new perspectives for fishing gear developments. Gear that is today considered inefficient would become profitable, opening the way for more energy-efficient gears with less impacts on the environment (Pauly et al. 2003).

We thus consider that reaching the MSY is a major undertaking, which will mobilize the whole sector for years to come, and revolutionize management methods. We know that efforts have already been undertaken, especially by implementing long term management plans and by defining a 2011-2015 transition scheme to MSY. However, we believe that the current debate does not consider sufficiently how to massively reduce fishing pressure without destroying the sector.

The transition phase represents the major difficulty. Initially, reducing fishing pressure will lead to reduced catches. Only once stocks are restored, after several years, will total catches return to equivalent or even higher levels. The transition must therefore be progressive; from this point of view, delaying measures to reach the 2015 MSY target (like the European Commission did until 2010, and like some European Ministers are still claiming) will make the transition economically and socially more difficult. Thus, the transition should possibly be subsidized. Of course, care should be taken to avoid repetition of the Canadian experience where subsidies during the cod moratorium were invested in increased fishing capacity (Rice et al., 2003). But national or European funding, currently allocated to fund fishing (for instance oil subsidies) could be directed towards economic and social support until the stocks have grown back. In any case, the transition requires strong political will, notably to avoid fishing pressure increases again at the first signs of stock recovery. All participants will have to accept not to take more fish, even if the abundances are multiplied by 3 or 4 . Otherwise, they risk returning to the previous situation.

Other difficulties, which can seem more technical but are nevertheless real, involve the estimation of MSY levels (usually based on single species approaches), the impossibility to reach MSY simultaneously for all the species and its use on an appropriate time scale of few years in the context of global change. These questions have to be resolved and compromises identified, relying notably on fleet based analyses and bioeconomic modeling (Grafton et al., 2007).

More generally, and beyond these technical difficulties, we believe that the goal of MSY is no longer justified by maximizing catches (as may have been the case when the theory was developed), but by decreasing the impact of fishing on exploited resources. This goal can be interpreted as taking into account an ethical point of view within fisheries policy. Man, because he profits from them, can legitimately impact ecosystems he is part of. But this impact is no longer ethically admissible if more damage is done to the ecosystem than strictly needed to achieve the expected result. The same catches as today can be obtained at much lower cost from much larger stocks and at much less impacted ecosystem. This ethical principle deserves to be extended beyond single species management (for instance to the assessment of impact on habitat). 


\section{Overcapacity is not everything, access rights must be regulated}

The European Commission in its green paper on reforming fisheries policies (EC, 2009) identified fleet overcapacity as the principle cause for the current difficulties, in particular overfishing. We think things are more complex. Overcapacity is the consequence of over-investment, at least for certain fleets. But it is also the result (a symptom) of the poor state of marine stocks and all quota reductions aggravate overcapacity (Clark et al., 1979; Clark and Munro 2002; World Bank and FAO, 2009).

The real cause of overfishing is that fishing mortalities are too high. This stems from fishing overcapacity, but also from fishing rights granted to each vessels. Thus, there is no simple relationship between fishing capacity and fishing mortality, nor between overcapacity and overfishing. The only thing that is certain is that a reduction in fishing mortality is required.

The recognition of social goals as an integral part of sustainable development, and the recognition of national planning goals can lead politicians to accept some fishing overcapacity. The economic and social motivations for any choice deserve to be analyzed on a local scale, taking into account all economic and social effects, including national heritage or cultural effects that would result from the disappearance of fishing or its regression below a certain threshold (Mascia et al., 2003).

In other words, we believe that fisheries problems cannot be resolved solely by tackling fishing capacity. Of course, certain capacity adjustments will be inevitable, notably in the case of the severely depleted stocks. However, it cannot be the only management measure. For halting the decline of the fishing sector, marked by successive vessel decommissioning plans, it is necessary to come up with methods for regulating access. This requires implementing a large range of management tools: fishing quotas, limiting days-at-sea, closed areas, licenses, etc.

\section{All management tools must be mobilized}

There is no silver bullet for reaching the ambitious goals of reducing fishing pressure to levels compatible with MSY, limiting discards, restoring ecosystems to good environmental status, and ensuring fisheries sustainability. All available management tools must be implemented and adapted for each fishery, embracing their complexity and accepting that different fisheries might require different solutions (Degnbol et al., 2006).

\section{- $\quad$ From quotas to ITQs?}

Quotas are limiting fishing pressure effectively, as long as scientific advice can rely on high quality catch data, management recommendations are followed and decisions are implemented. This system is today a cornerstone of fisheries management in Europe. It must be maintained and strengthened in view of reaching MSY in a few years. In addition, the introduction of ITQs is often presented as the solution to the difficulties facing fisheries (e.g. Arnason, 1996; Squires et al., 1995; EC, 2009) and is supported by national experiments in some European countries. We have three remarks:

1. What determines the effectiveness of quotas in terms of conservation is obviously their overall level, and also their enforceability, but not their transferability. In other words, it is the total quota and not the ITQ that is a management tool for reaching the goal of ecological sustainability. ITQs aim to reach economic efficiency.

2. In most of the European fisheries, the individualization of quotas contributes to empowering fishers enabling them to avoid over-investment. It also aims at improving enforcement by increasing compliance and commitment through ownership mechanisms. If it is complemented by an effective control of discards, individual quotas can be a powerful tool for promoting good practice, especially regarding energy savings, limiting economic impacts, improving product quality, etc. 
3. Numerous economic studies have shown that the transferability of quotas presents a certain number of risks: speculation on transfer costs, concentration within a few fishing fleets and exclusion of artisanal fishers (e.g. Hersoug, 2002; Flaaten, 2010; Marchal et al., 2009).

Thus, nothing guarantees that an ITQ system will respond simultaneously to sustainable ecological, economic and social goals. Even if individualization seems desirable in the European context, the management method mostly remains to be invented to satisfy the needs for transparency, equity and social regulation. Whether the quotas are administered, collectively managed (notably by producer's organizations) or transferable and accompanied by regulation rules, the choice will necessarily depend on a compromise among actors and decisions of an eminently political nature.

\section{- $\quad$ Limiting effort, modifying gears and developing MPAs}

Quota system must be complemented by different types of measures. Some are not fundamentally new, but deserve to be more widely applied. Measures to directly limit fishing effort should be strengthened (operating licenses, days-at-sea quotas, biological rest periods, etc). Reinforced technical measures could have positive effects on certain stocks: increase in legal mesh size and/or sizes, development of escape or avoidance devices, modified fishing gear.

MPAs play an essential role, particularly in conserving biodiversity, preserving sensitive habitats and species, protecting essential habitats (notably reproduction and nursery zones), and reducing fishing pressure (e.g. Gell and Robert, 2003; Lester et al., 2009). Additionally, they constitute pilot areas that contribute to developing participatory, integrated ecosystem management approaches (Boncoeur et al. 2002) and could be a key ingredient for small scale fisheries (Hilborn et al., 2004).

Nevertheless, as important as it is, the protection of one part of the marine territory is not sufficient for an ambitious and sustainable fisheries policy. If we are not careful, the sectorization of the sea could even become counter-productive. On one side, it would create reserve zones where nature would be effectively preserved (but for the benefit of whom?). And on the other side, it would leave vast zones devoid of protection, where an excessive number of fishers would compete for a rare resource. In other words, as with any other management method, MPAs are not a silver bullet. They can be fully effective integrated into an overall policy of marine resource based on marine spatial planning and ecosystem management (Hannesson, 1998; Hilborn et al., 2004).

- $\quad$ Ecolabelling: A useful tool, if...

Ecolabelling represents an interesting tool to encourage producers to engage in good management practices under the pressure of new consumer demands (Wessels et al., 1999; Brécard et al., 2009). One can question its short-term financial advantages as a factor of product differentiation, but not the fact that they interest retailers, environmental NGOs and consumers. Consequently, ecolabels can create useful incentives for responsible management (Salladarré et al., 2010).

Thus, the development of ecolabels should be encouraged, provided these labels are based on the definition and respect of rigorous specifications, including: healthy stocks (return to MSY), low ecosystem impact, respect of social fairness criteria (wages, safety, etc.), effective management systems, independence of certifying and accrediting bodies (conform with FAO criteria), and low energy consumption.

\section{- $\quad$ Redistributing subsidies}

Initially, the vision of the CFP underpinning public financial support, copied from agriculture, was based on intensive mode of production. It is clear that this development model has reached its limits (as in agriculture). Because of overfishing, fishing revenues no longer suffice to absorb the excessive costs caused by over-investment. Excessive debts are, as admitted by several professional representatives, the number one cause of irresponsible fishing and endangering the safety of seamen (Sumaila et al., 2008; World Bank and FAO, 2009). A continuous flow of aid is currently required, in particular in France, to keep the businesses just afloat. The social result is also catastrophic: between 1970, the beginning of the structural funds, and 1990, just before the first scrapping plan, "modernization" sacrificed 8,000 marine jobs (22\% of the workforce) in France, while average vessel power was multiplied by 2.3 (Mesnil, 2008). 
Of course we know that fisheries must adapt and modernize; and we also know that technical progress and productivity gains may lead to job losses. But in this context current subsidies are mainly justified by the short term search for social peace, contributing in fact to maintain archaic practices without any vision of the long term sustainable development of the fishing sector.

It is time to get off the wrong track. Public support should only be granted to accompany transitions to sustainable fishing and restored ecosystems, easing the associated economic and social shortterm costs.

\section{Conclusion: Implementing medium term management plans for a sustainable development}

Medium-term management plans are required to combine different measures and to compromise between medium or long term goals and short term transition costs. They should also integrate multi-species and multi-fleet considerations. Once the management goals are defined (in collaboration with all actors, and under the control of public authorities), fishers have an essential role to play in determining the most effective tools for regulating fishing mortality. The role of scientists is to provide insights by evaluating the effects of past measures, trying to understand and explain past dynamics and anticipating the potential effects of different management options.

In several texts, the European Commission seems to promote a situation in which industrial fisheries would be managed by ITQs, applying strict criteria of economic efficiency, while social goals would also be included for small scale and coastal fisheries (see for instance the green paper: EC, 2009). This approach seems incompatible with sustainable development principles, which stipulate that ecological, economic and social goals must apply to the entire industry and thus to all fleets. This does not mean that all fisheries are equivalent. But industrial fisheries can not be exempted from ecological and social issues. As for small scale fisheries, the goal is certainly not to preserve certain fishing practices or certain coastal communities, like in a museum. The triple balance sheet ecological, economic and social - must be established for each fleet. And it is on this triple balance sheet that the choices of the common fishing policy must be made.

Implementing these various management measures may seem restrictive. However, this is the price to pay to avoid managing by simply decreasing fishing capacity, or in the absence of any management the ruin of numerous fisheries. We observe already now that there are lots of forces in the move to try to stop the European fisheries decline. All stakeholders have to be involved to turn from the decline to the sustainable use of marine resources. The fishing industry is a sector where mankind encountered most drastically ecosystem limits. Not only future generations will be impacted, but the present ones are already. Changing and building a future for marine Fisheries in Europe will be difficult and costly; but it would be the test of our common capacity to find the way of sustainable development for our societies.

\section{References}

Abernthy, KE. Trebilcock, P., Kebede, B., Allison, E.H., Dulvy, N.K. 2010. Fuelling the decline in UK fishing communities? ICES Journal of Marine Science, 67: 1076-1085.

Anderson J.L. (Ed.), 2003. The international seafood trade, CRC (USA) \& Woodhead Publishing Ltd, Cambridge (UK), 222p.

Arnason R., 1996. On the ITQ fisheries management system in Iceland, Reviews in Fish Biology and Fisheries, 6: 63-90.

Boncoeur J, Alban F, Guyader O, Thebaud O., 2002. Fish, fishers, seals and tourists: economic consequences of creating a marine reserve in a multi-species, multi-activity context. Natural Resource Modeling 15: 387-411.

Brécard, D., Hlaimi B., Lucas S., Perraudeau Y., Salladarré F., 2009. Determinants of demand for green products: An application to eco-label demand for fish in Europe, Ecological Economics, 69: 115-125. 
Clark C.W., Clarke F.H., Munro G.R., 1979. The optimal exploitation of renewable resource stocks: problems of irreversible investment, Econometrica, 47: 25-47.

Clark C.W., Munro G.R., 2002. The problem of overcapacity, Bull. of Mar. Sci., 70:473-483.

Cléach M.P., 2009. Marée amère : pour une gestion durable de la pêche, Rapport de l'Office parlementaire d'évaluation des choix scientifiques et technologiques n¹32, Assemblée Nationale, Paris, 175 pp.

Degnbol P, Gislason H, Hanna S, Jentoft S, Nielsen JR, Sverdrup-Jensen S, Wilson JD (2006) Painting the floor with a hammer: Technical fixed in fisheries management. Marine Policy, 30: 534-543.

EC (European Commission), 2002. Council Regulation (EC) No 2371/2002 of 20 December 2002 on the conservation and sustainable exploitation of fisheries resources under the Common Fisheries Policy. Official Journal of the European Union, L 358 31/12/2002.

EC (European Commission), 2008. Directive 2008/56/EC of the European Parliament and of the Council of 17 June 2008 establishing a framework for community action in the field of marine environmental policy (Marine Strategy Framework Directive). Official Journal of the European Union, L 164/19 25/6/2008: 1940.

EC (European Commission), 2009. Green Paper: Reform of the Common Fisheries Policy. COM (2009) 163 final. EC, Brussels, $27 \mathrm{p}$.

EC (European Commission), 2010. Consultation on Fishing Opportunities for 2011, COM(2010) 241. EC, Brussels, $20 \mathrm{p}$.

FAO (Food and Agriculture Organisation), 2003. Report of the Expert Consultation on Ecosystem-based Fisheries Management. Reykjavik, Iceland, 16-19September 2002. FAO Fisheries Report No. 690, Rome, FAO. 23p.

FAO (Food and Agriculture Organisation), 2009. The State of World Fisheries and Aquaculture, 2008. FAO, Rome. $176 \mathrm{p}$.

Flaaten O., 2010. Fisheries rent creation and distribution - the imaginary case of codland, Marine Policy, 34: 1268-1272.

Froese R., Proelss A., 2010. Rebuilding fish stocks no later than 2015: will Europe meet the deadline? Fish and fisheries, 11: 194-202.

Froese R., Branch T., Proelß A., et al., 2010. Generic harvest control rules for European fisheries, Fish and fisheries, Article first published online, Doi: 10.1111/j.1467-2979.2010.00387.x

Froese R., Stern-Pirlot A., Winker H., Gascuel D., 2008. Size Matters: How Precautionary Single-Species Management Can Contribute To Ecosystem-based Fisheries Management. Fisheries Research, 92: 231-241.

Garcia S. M., Zerbi A., Aliaume C., et al., 2003. The ecosystem approach to fisheries, FAO Fisheries Technical Paper No. 443, Rome, FAO. 71 p.

Gell F.R., Roberts C.M., 2003. Benefits beyond boundaries: the fishery effects of marine reserves. Trends in Ecology and Evolution, 18(9): 448-455.

Grafton R.Q., Kompas T., Hilborn R.W., 2007. Economics of overexploitation revisited, Science, 318: 16011607.

Halpern B.S., Walbridge S., Selkoe K.A., et al., 2008. A global map of human impact on marine ecosystems. 2008 - Science, 319(5865): 948-952.

Hannesson R., 1998. Marine Reserves: What would they accomplish? Marine Resource Economics, 13: 159170.

Heath M.R., 2005. Changes in the structure and fuction of the North Sea fish foodweb, 1973-2000, and the impacts of fishing and climate. ICES Journal of Marine Science, 62: 847-868.

Hersoug B., 2002. Unfinished business: New Zealand's experience with rights-based fisheries management, Eburon: Delft, Netherlands, $246 \mathrm{p}$.

Hilborn R., 2010. Apocalypse forestalled: Why all the world's fisheries aren't collapsing. Nature Conservancy. Cool Green Science Blog, (http://blog.nature.org)

Hilborn R., Stokes K., Maguire J.J., Smith T., Botsford L.W., Mangel M., Orensanz J., Parma A., Rice J., Bell J., Cochrane K.L., Garcia S., Hall S.J., Kirkwood G.P., Sainsbury K., Stefansson G., Walters C., 2004. When can marine reserves improve fisheries management? Ocean and Coastal Management, 47: 197-205.

Hutchings J.A., Minto C., Ricard D., et al., 2010. Trends in the abundance of marine fishes, Can. J. Fish. Aquat. Sci., 67: 1205-1210.

ICES, 2009. Report of the ICES Advisory Committee, 2009. ICES, Copenhaguen, Danmark, 95 p. 
Jackson J.B., Michael X.K., Wolfgang H.B., et al., 2001. Historical Overfishing and the Recent Collapse of Coastal Ecosystems, Science, 293: 629-638.

Jansson A.M., Hammer M., Folke C., Costanza R. (Eds), 1994. Investing in natural capital: the ecological economics approach to sustainability, Island Press.

Lester S.E., Halpern B.S., Grorud-Colvert K., Lubchenco J., Ruttenberg B.I., Gaines S.D., Airamé S., Warner R.R., 2009. Biological effects within no-take marine reserves: a global synthesis. Marine Ecology Progress Series, 384: 33-46.

Lorance P., Bertrand J-A., Brind'Amour A., Rochet M-J., Trenkel V., 2009. Assessment of impacts from human activities on ecosystem components in the Bay of Biscay in the early 1990s. Aquatic Living Resources, 22: 409-431.

Marchal P., Lallemand P., Stockes K., Thébaud O., 2009. A comparative review of the fisheries resource management in new Zealand and in the European Union. Aquatic Living Resources. 22: 463-481.

Mardle S., Pinnegar J.K., Hill A., 2008. Economic effects of the cod recovery plan on the mixed fisheries in the North Sea (EcoCoRP), Final Report February 2008 for The European Commission, Directorate-General for Fisheries, $184 \mathrm{pp}$.

Mascia M.B., Brosius J.P., Dobson T.A., et al., 2003. Conservation and the social sciences, Conservation Biology, 17: 649-650.

MEA (Millennium Ecosystem Assessment), 2005. Ecosystems and Human Well-being : Synthesis, Island Press, Washington, DC. 138 pp.

Mesnil B., 2008. Public-aided crises in the French fishing sector, Ocean \& Coastal Management, 51: 689-700.

OSPAR Commission, 2010. Quality status report 2010. OSPAR Commission, London,176 p

Pauly, D. 2009. Beyond duplicity and ignorance in global fisheries. Scientia Marina, 73: 215-224.

Pauly D., Alder J., Bennett E., et al., 2003. The future of fisheries, Science, 302: 1359-1361.

Pauly D, Christensen V, Dalsgaard J, et al., 1998. Fishing down marine food webs, Science, 279: 860-863.

Pauly D., Watson R., Alder J., 2005. Global trends in world fisheries: impacts on marine ecosystems and food security. Philosophical Transactions of the Royal Society B-Biological sciences, 360(1453): 5-12.

Rice J.C., Shelton P.A., Rivard D., Chouinard G.A., Fréchet A., 2003. Recovering Canadian Atlantic cod stocks: the shape of things to come? ICES Annual Science Conference, CM 2003/U:06, p 23.

Rice J.C., 2006. Every which way but up: the sad story of Atlantic groundfish, featuring Northern cod and North Sea cod. Bulletin of Marine Science, 78(3): 429-465.

Rochette S., Rivot E., Morin J., Riou P., Le Pape O., 2010. Effect of nursery habitat degradation on flatfish population: Application to Solea solea in the Eastern Channel (Western Europe). Journal of Sea Research, 64: 34-44.

Salladarré F., Guillotreau P., Perraudeau Y., Monfort M.-C., 2010. The demand for seafood eco-labels in France: public image of fisheries and other determining factors, Journal of Agriculture, Food and Industrial Organization, vol. 8(1), DOI: 10.2202/1542-0485.1308.

Serchuk F.M., Kirkegaard E., Daan N., 1996. Status and trends of the major roundfish, flatfish, and pelagic fish stocks in the North Sea : thirty-year overview. ICES Journal of Marine Science, 53: 1130-1145.

Sparholt H., Bertelsen M., Lassen H., 2007. A meta-analysis of the status of ICES fish stocks during the past half century. ICES Journal of Marine Science, 64(4): 707-713.

Squires D., Kirkley J. Tisdell C.A., 1995. Individual transferable quotas as a fisheries management tool, Reviews in Fisheries Science, 3:141-169.

Sumaila U.R., The L., Watson R., et al., 2008. Fuel price increase, subsidies, overcapacity, and resource sustainability, ICES J. of Mar. Sci., 65:832-840.

Turner S.J., Thrush S.F., Hewitt J.E., Cummings V.J., Funnell G., 1999. Fishing impacts and the degradation or loss of habitat structure. Fisheries Management and Ecology, 6(5): 401-420.

UNCLOS, 1982. United Nations Convention on the Law of the Sea. 1833 UNTS 3. In Froese et al., 2010.

UNFSA, 1995. Agreement for the Implementation of the Provisions of the United Nations Convention on the Law of the Sea of 10 December 1982, Relating to the Conservation and Management of Straddling Fish Stocks and Highly Migratory Fish Stocks. 2167 UNTS 88. In Froese et al., 2010.

Villasante S., 2010. Global assessment of the European Union fishing fleet: An update. Marine Policy, 34: 663670. 
Wessells, C. R., Johnston, R. J., Donath H., 1999. Assessing consumer preferences for eco-labeled seafood: the influence of species, certifier, and household attributes, American Journal of Agricultural Economics, 81: $1084-1089$

World Bank and FAO, 2009. The sunken billions: The economic justification for fisheries reform. Washington DC: The World Bank and Food and Agriculture Organization of the United Nations.

Worm B., Barbier E.B., Beaumont N., et al., 2006. Impacts of biodiversity loss on ocean ecosystem services, Science, 314: 787-790.

Worm B., Hilborn R., Baum J. et al., 2009. Rebuilding Global Fisheries. Science, 325: 578-584. 